\title{
Update on Engine Combustion Research at Sandia National Laboratories
}

\author{
Jay Keller \\ Sandia National Laboratories \\ Gurpreet Singh \\ Department of Energy
}


SAE routinely stocks printed papers for a period of three years following date of publication. Direct your orders to SAE Customer Sales and Satisfaction Department.

Quantity reprint rates can be obtained from the Customer Sales and Satisfaction Department.

To request permission to reprint a technical paper or permission to use copyrighted SAE publications in other works, contact the SAE Publications Group.

This article was prepared as an account of work sponsored by an agency of the United States

Government. Neither the United States Government nor any agency thereof, nor any of their employees, makes any warranty, express or implied, or assumes any legal liability or responsibility for the accuracy, completeness, or usefulness of any information, apparatus, product, or process disclosed, or represents that its use would not infringe privately owned rights. Reference herein to any specific commercial product, process, or service by trade name, trademark, manufacturer, or otherwise does not necessarily constitute or imply its endorsement, recommendation, or favoring by the United States Government or any agency thereof. The views and opinions of authors expressed herein do not necessarily state or reflect those of the United States Government or any agency thereof.

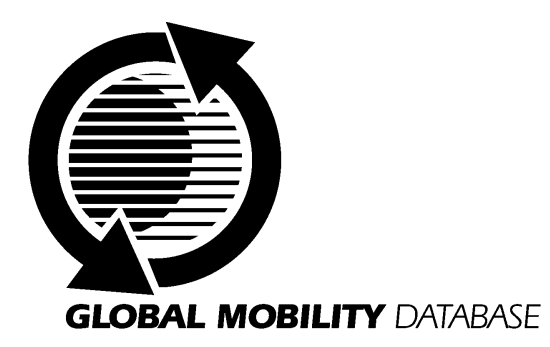

All SAE papers, standards, and selected books are abstracted and indexed in the Global Mobility Database

ISSN 0148-7191

No copyright is asserted in the works of U.S. Government employees.

Positions and opinions advanced in this paper are those of the author(s) and not necessarily those of SAE. The author is solely responsible for the content of the paper. A process is available by which discussions will be printed with the paper if it is published in SAE Transactions. For permission to publish this paper in full or in part, contact the SAE Publications Group.

Persons wishing to submit papers to be considered for presentation or publication through SAE should send the manuscript or a 300 word abstract of a proposed manuscript to: Secretary, Engineering Meetings Board, SAE.

\section{Printed in USA}




\title{
Update on Engine Combustion Research at Sandia National Laboratories
}

\author{
Jay Keller \\ Sandia National Laboratories \\ Gurpreet Singh \\ Department of Energy
}

No copyright is asserted in the works of U.S. Government employees.

\begin{abstract}
The objectives of this paper are to describe the research efforts in diesel engine combustion at Sandia National Laboratories' Combustion Research Facility and to provide recent experimental results. We have four diesel engine experiments supported by the Department of Energy, Office of Heavy Vehicle Technologies: a onecylinder version of a Cummins heavy-duty engine, a diesel simulation facility, a one-cylinder Caterpillar engine to evaluate combustion of alternative fuels, and a homogeneous-charge, compression-ignition $(\mathrm{HCCl})$ engine. Recent experimental results of diesel combustion research will be discussed and a description will be given of our $\mathrm{HCCl}$ experimental program and of our $\mathrm{HCCl}$ modeling work.
\end{abstract}

\section{INTRODUCTION}

Diesel engines play an important role in the U.S. economy accounting for nearly all of the engines in the class 7 and 8 categories. The Engine Combustion Department of Sandia National Laboratories' Combustion Research Facility has four laboratories supported by the Department of Energy Office of Heavy Vehicle Transportation Technologies: a one-cylinder version of a Cummins heavy-duty engine, a diesel combustion simulation facility, a one-cylinder Caterpillar engine used to evaluate combustion of alternative fuels, and a homogeneous-charge, compression-ignition $(\mathrm{HCCl})$ engine. The research conducted in these laboratories support the heavy-duty diesel engine manufacturers by providing fundamental understanding of the combustion processes that control engine efficiency and emission formation.

This paper is intended to briefly describe the facilities and projects and present recent results. It is divided into four sections focusing on each of the experiments. This paper draws from several recent publications and provides a current summary of our progress in understanding the in-cylinder diesel combustion processes.

\section{SPECIFIC EXPERIMENTS}

Each section will discuss a specific experiment and recent results.

SANDIA/CUMMINS HEAVY-DUTY ENGINE - The development of new heavy-duty engine designs that reduce pollutant emissions while maintaining or improving engine performance requires an understanding of in-cylinder combustion and emissions formation processes. Laser-imaging diagnostics are uniquely capable of providing this information. Previous laser-imaging studies have generally focused on free diesel jets; impingement of the combusting plume on incylinder walls was not examined in detail. The understanding of the interaction of a combusting diesel plume with in-cylinder surfaces, which may affect exhaust soot emissions because of wall deposition and subsequent blow-off, is incomplete. Two different sets of optical experiments were conducted to examine diffusion-flame/wall interactions and in-cylinder soot deposition.

Simultaneous $\mathrm{OH}$ planar laser-induced fluorescence (OH-PLIF) and planar laser-induced incandescent (PLII) soot imaging was previously demonstrated in this engine [1]. Recently, these studies were extended to examine flame-wall interactions [2]. In addition, a laser-light extinction technique was developed to measure the rate of soot deposition on in-cylinder surfaces, using a standard diesel fuel and three different compositions of 
an oxygenated fuel blend, over a wide range of operating conditions [3].

Experimental hardware - The engine is a one-cylinder version of the Cummins $\mathrm{N}$-series 4-stroke production diesel engine. The $\mathrm{N}$-series engine is typical of heavyduty size-class diesel engines (class $7 \& 8$ ), with a bore of $140 \mathrm{~mm}$ and a stroke of $152 \mathrm{~mm}$. These dimensions are retained in the optical-access engine, and a production Cummins $\mathrm{N}$-series cylinder head is used so that the production engine intake port geometry is also preserved. The design of this engine utilizes a classic extended piston with piston-crown window, and windows are also installed in the cylinder head (in place of one of the exhaust valves) and near the top of the cylinder wall. For these experiments, an additional window was installed in the bowl-rim of the piston, providing a transparent wall surface for studying impingement. A complete description of this engine and bowl-rim window is provided in Ref. 2 .

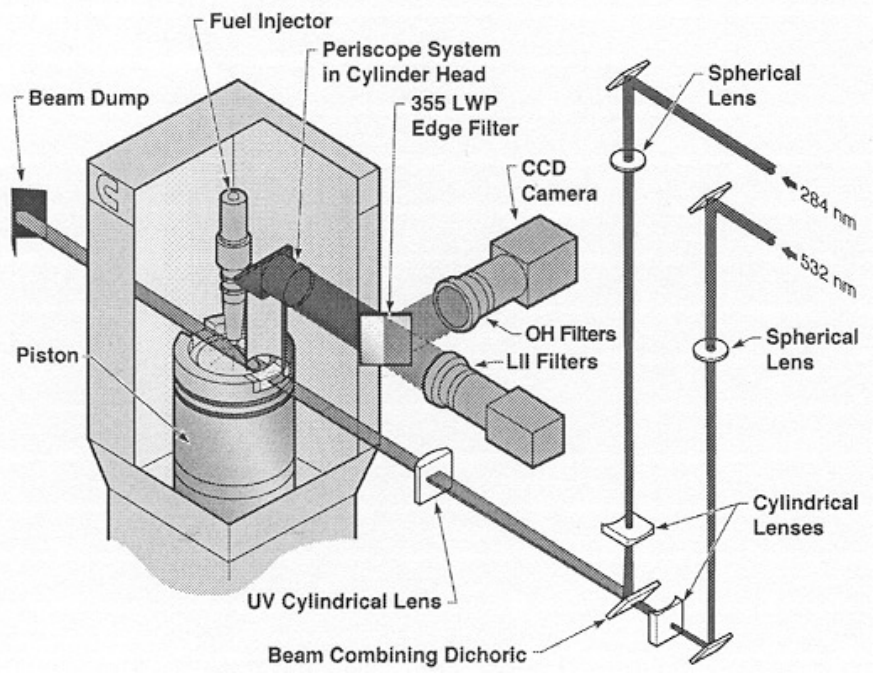

Figure 1. Schematic of the optical-access diesel engine showing the optical setup for simultaneous OH-PLIF and PLII-soot imaging. Only one of the 7 fuel jets is shown.

In the first set of experiments, a dual-laser, dual-camera system was used to obtain the simultaneous "singleshot" images of OH PLIF and soot PLII, as shown in Fig. 1. The two laser beams were combined into overlapping laser sheets approximately $25 \mathrm{~mm}$ wide and $0.2 \mathrm{~mm}$ and $0.3 \mathrm{~mm}$ thick for the PLIF and PLII lasers, respectively, as shown in Fig. 1. The combined beams were directed into the combustion chamber through a window at the top of the cylinder wall that was inline with the bowl rim window and one of the jets of the 7-hole injector (the opposite jet is "missing" [2]). The OH PLIF and soot PLII emissions were separated with a spectral filter, and images were acquired through a periscope system in the cylinder head, that provides a top-view of the outer bowl and squish region, and edge of the bowl rim window.
In the second set of experiments, the transmission of a $\mathrm{CW}$ diode laser passing horizontally through the combustion chamber was continuously recorded over many engine cycles. Measurements of the change in the transmission through the combustion chamber with each fired cycle were used to determine the soot deposition rate on the bowl-rim window.

Recent results - As shown in Fig. 2, images of $\mathrm{OH}$ fluorescence show that the diffusion flame near the head of the jet remains thin, and the bowl-rim wall appears to have little or no effect on the overall shape of the plume until the leading edge contacts the wall. After contact, the diffusion flame first flattens along the wall surface, and is then extinguished within $70 \mu$ s of first contact.

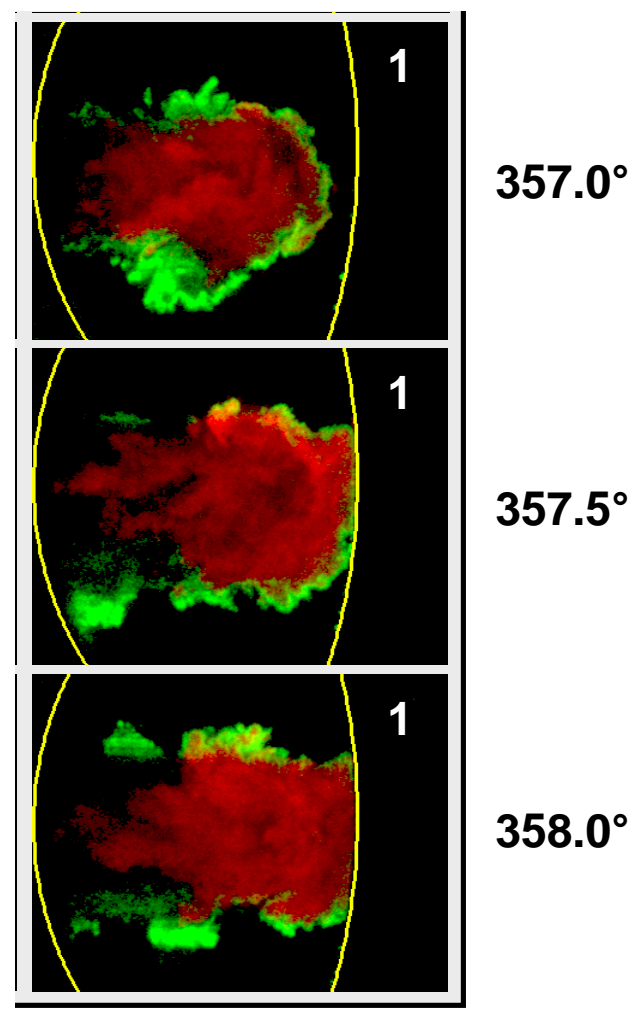

Figure 2. Temporal sequence of simultaneous $\mathrm{OH}$ (green) and soot (red), viewed through the cylinder head window. The yellow curve at the right marks the edge of the bowl wall and the field of view is $30 \mathrm{~mm}$ by $22 \mathrm{~mm}$.

PLII images show that after the diffusion flame is extinguished, the soot in the core of the jet is transported very close to the wall, providing a source of soot for possible deposition mechanisms such as thermophoresis.

The laser attenuation measurements show that the attenuation of the laser through the soot layer (and bowl rim window) increases logarithmically with each fired cycle, in accordance with classical absorption theory. The rate of deposition varied linearly with the oxygen content in the oxygenated fuel. The deposition rate for standard diesel fuel exceeded an extrapolation of this 
linear relationship (at zero oxygen content) by a factor of three, suggesting soot deposition rates may not be predicted from fuel oxygen content alone.

Some of the conclusions from these two recent studies follow:

1. Soot deposition on in-cylinder surfaces occurs in regions where the combusting plume contacts the wall and the diffusion flame is extinguished, allowing transport of soot to the wall.

2. Changes in operating conditions (injection timing, EGR/diluent addition) has little effect on the soot deposition rate in this engine.

3. As the soot layer thickens, the net soot accumulation rate steadily decreases, suggesting that either the deposition rate decreases or the removal/oxidation rate increases.

4. As engine operating conditions are changed, variations in the rate of soot deposition do not correlate with changes in exhaust soot emissions, indicating that in-cylinder soot wall-deposition/ blowoff is not a primary contributor to exhaust soot emissions.

DIESEL COMBUSTION SIMULATION FACILITY - After the autoignition phase is completed on a diesel spray, the flame propagates back upstream toward the injector and stabilizes at a quasisteady location downstream of the injector. The distance between the injector and the flame location is referred to as the lift-off length (or height). There is growing evidence to suggest that the flame lift-off length plays a significant role in DI diesel combustion and emission processes, making lift-off length of significant practical importance to diesel engines. Flame lift-off is believed to affect diesel combustion and emission processes by allowing fuel and air to premix prior to reaching the initial combustion zone in a diesel spray (i.e., the lift-off length). For a moderateload condition in a heavy-duty engine, fuel concentration measurements and air entrainment estimates indicate that as much as $20 \%$ of the air required to burn the injected fuel is entrained and mixed with fuel upstream of the lift-off length [4].

The goals of this research were several-fold. The first was to present a comprehensive picture of how several primary engine parameters affect lift-off length. The second was to investigate how the fuel-air mixing upstream of the lift-off is affected by various parameters. The third was to determine how the fuel-air mixing upstream of the lift-off length affects soot formation in a DI diesel spray. The final goal was to determine how changes in the lift-off length affect the relationship between fuel vaporization and combustion.

The parameters varied in the experiments included: ambient gas temperature and density, injection pressure, and orifice diameter. The lift-off length data discussed in following sections summarizes data presented Siebers and Higgins [5-7].

Experimental hardware and measurements - The diesel spray investigations discussed in the following section were conducted in a constant-volume combustion vessel with extensive optical access. This facility is discussed in detail in other publications $[4,8]$. Fuels were injected with an electronically controlled, common-rail injector using a single-hole orifice, i.e., a single-spray plume was considered.

Images of $\mathrm{OH}$ chemiluminescence were acquired and analyzed to determine lift-off length. The distance between the injector and the upstream location of $\mathrm{OH}$ chemiluminescence in an image was defined as the liftoff length. A photodiode was also used to measure the total soot incandescence from the spray simultaneously with the acquisition of the $\mathrm{OH}$ chemiluminescence image. The soot incandescence measurements were used to determine the relative effect of lift-off length and the concomitant fuel-air premixing on soot formation in the fuel spray. The $\mathrm{OH}$ chemiluminescence and soot incandescence measurements were coupled as needed with previous gas-phase penetration, liquid-phase fuel penetration, and spreading angle measurements for sprays obtained under the same conditions $[4,9]$.

Recent results - The results show that lift-off length can vary widely with in-cylinder and injector conditions. The major effects of various parameters on lift-off length observed in the experiments were:

1. Ambient gas temperature and density have strong, non-linear effects on lift-off length. An increase in either parameter causes a decrease in lift-off length. However, the sensitivity of lift-off length to both parameters decreases as they increase. This is shown in Fig. 3, a plot of lift-off length as a function of ambient gas temperature for several ambient gas densities.

2. The decrease in lift-off length with increasing temperature is the net result of temperature effects on the laminar flame speed and the thermal diffusivity.

3. Only part of the decrease in lift-off length with increasing density can be explained by densityinduced changes in the laminar flame speed and the thermal diffusivity. The remaining portion of the decrease is most likely due to density effects on the spray development.

4. Lift-off length decreases with decreasing orifice diameter. This effect is different than that noted for gas jets, which show no lift-off length dependence on orifice diameter [e.g., 10].

5. Lift-off length increases with increasing injection pressure. The dependence is linear with respect to the injection velocity, the same as noted for gas jets [e.g., 10]. 


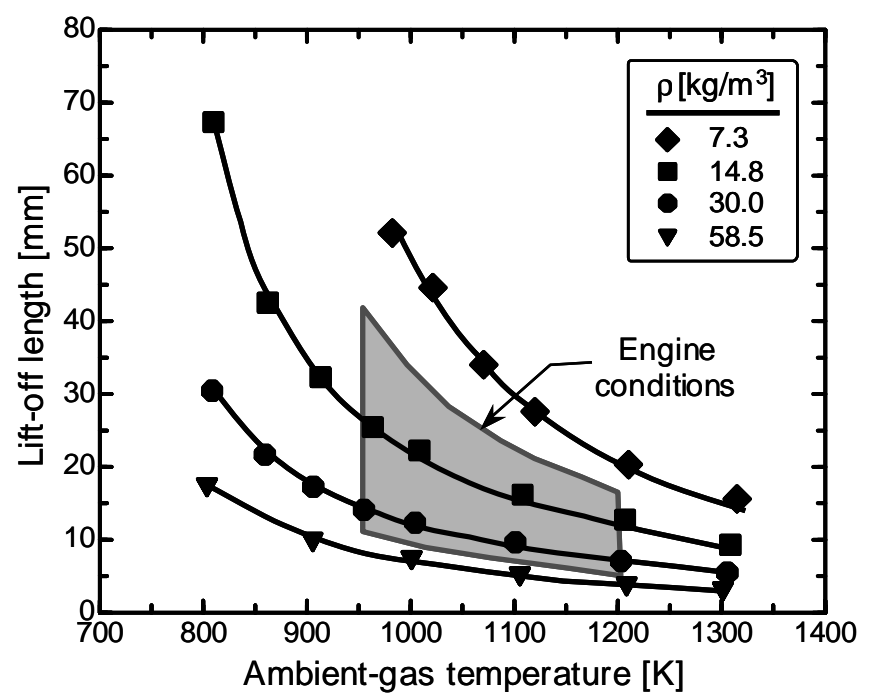

Figure 3. Lift-off length versus ambient gas temperature for a range of ambient gas densities, $\rho$. The pressure drop across the injector orifice and orifice diameter were $138 \mathrm{MPa}$ and $180 \mu \mathrm{m}$. The gray region represents the range of lift-off lengths expected in (quiescent) engines. The curves through the data represent the trends along lines of constant density. The lift-off length repeatability is $\pm 7 \%$.

Estimates of the total air entrainment up to the lift-off length relative to the amount of air required to completely burn the injected fuel (i.e., the percent of stoichiometric air entrainment) provided insights on the amount of fuelair mixing that occurs prior to combustion as a result of flame lift-off:

1. The percent of stoichiometric air entrainment increases as lift-off length increases with either decreasing temperature or increasing injection pressure. The changes in the percent of stoichiometric air entrainment for both of these parameters are due solely to the changes in the liftoff length.

2. Changes in ambient gas density have little effect on the percent of stoichiometric air entrainment at the lift-off length. The lack of effect occurs because changes in the percent of stoichiometric air entrainment caused by density induced changes in the lift-off length are nearly compensated by density induced changes in the air entrainment rate.

3. In spite of the decrease in lift-off length with decreasing orifice diameter, the percent of stoichiometric air entrainment strongly increases with decreasing orifice diameter. This trend occurs because air entrainment into a spray relative to the amount of fuel injected increases linearly with orifice diameter [9], overshadowing the lesser effect of orifice diameter on air entrainment through changes in the lift-off length.

4. Overall, the air entrainment estimates suggest that changes in intake air temperature, orifice diameter, and injection pressure will affect the amount of fuelair premixing prior to combustion in a diesel spray.
However, changes in the density at intake valve closing will have very little effect.

Together, the soot incandescence measurements and air entrainment estimates indicate that there is a strong link between the fuel-air mixing that occurs upstream of the lift-off length and soot formation in a diesel spray. Soot formation decreases as the amount of fuel-air premixing increases, becoming negligible when the air entrainment is sufficient to reduce the equivalence ratio to less than approximately two at the lift-off length. This is indicated by the soot incandescence measurements plotted in Fig. 4 as a function of the percent of stoichiometric air entrained upstream of the lift-off length. As the percent of stoichiometric air entrainment approaches $50 \%$, which corresponds to an average equivalence ratio of two in the spray, the soot incandescence approaches zero, indicating negligible

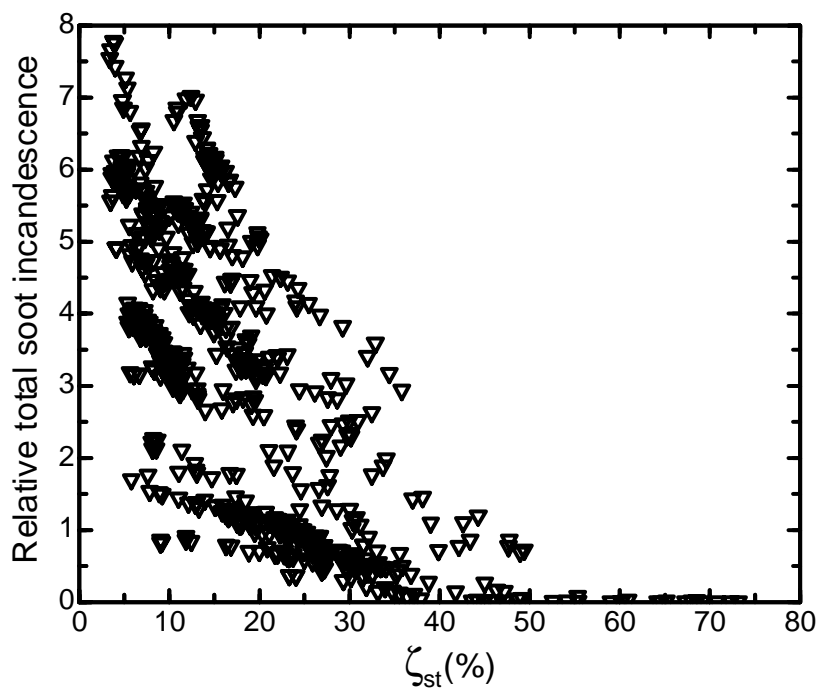

Figure 4. The relative total soot incandescence versus the percent of stoichiometric air entrained up to the lift-off length. Data are shown for ambient gas densities from 7.3 to $58.5 \mathrm{~kg} / \mathrm{m}^{3}$, ambient gas temperatures from 800 to $1300 \mathrm{~K}$, injection pressures from 40 to $190 \mathrm{MPa}$, and orifice diameters from 100 to $363 \mu \mathrm{m}$.

soot formation. The soot trends observed may partially explain the changes in soot emissions from engines noted with various parameters. For example, part of the reduction in soot emissions noted in engines as injection pressure is increased is very likely due to the increased air entrainment upstream of any combustion that results from an increase in the lift-off length with increasing injection pressure.

Comparison of the lift-off lengths from this work and previously measured liquid lengths show that the relationship between fuel vaporization and combustion changes with conditions. Lower densities and temperatures, smaller orifice diameters, and higher injection pressures allow more or even complete fuel vaporization prior to reaching the lift-off length, i.e., upstream of any combustion. Under these conditions, 
fuel vaporization is dominated by the entrainment of hot ambient gases. On the other hand, higher densities and temperatures, larger orifice diameters, and lower injection pressures result in less fuel vaporization prior to reaching the lift-off length. For these latter conditions, liquid-phase fuel can extend significantly downstream of the lift-off length in the central region of the spray. Combustion and vaporization under these conditions in all likelihood will interact with each other.

The results presented imply that the overall nature of the DI diesel combustion process under quiescent conditions and the relationships between various processes occurring in a DI diesel spray are not fixed. Over time, changes in in-cylinder and injector conditions made to meet increasingly stringent emissions regulations and new performance goals have led to an evolution of $\mathrm{DI}$ diesel combustion. This evolution is likely to continue in the future, as new design constraints are placed on engine designers. Results such as those presented in this work are helping explain in more detail the mechanisms behind the observed effects of changes in in-cylinder and injector conditions on combustion and emission processes in DI diesels.

SANDIA/CATERPILLAR ENGINE - The potential of oxygenated molecules ("oxygenates") blended with diesel fuel to reduce emissions of particulate matter (PM) from heavy-duty engines is well documented in the literature. The most pronounced effects are typically observed at high loads and at highly-retarded injection timings used for $\mathrm{NO}_{x}$ control. The detailed mechanisms by which oxygenates reduce PM emissions are not well understood, however. The literature contains conflicting results regarding the importance of molecular structure, carbon-carbon bonds, chemical-kinetic pathways, and overall blend oxygen content in determining the PMreduction potential of one oxygenate relative to another.

In addition, the effects of fuel property variations on incylinder mixing, ignition, and combustion processes are not well understood, especially in the case of oxygenates with physical and chemical properties that are vastly different from traditional diesel fuel. These and other effects must be understood for engine designers to use fuel properties to greatest advantage in meeting current and future emissions regulations. For instance, glow plug (GP) assisted ignition is a poorly-understood process that is important for cold-start performance and for the utilization of low-cetane fuels.

The focus of oxygenated-fuel research at Sandia is to investigate limiting cases to gain insight into the most important differences between combustion and emissions-formation processes of traditional diesel fuel and oxygenated fuels. One interesting limiting case that has been studied recently is GP-assisted ignition and combustion of neat methanol [11]. Neat methanol, denoted M100, was selected because: 1) it contains $50 \%$ oxygen by weight and therefore represents an upper limit on oxygenation; and 2) its cetane number is $<5$ so it also represents a lower limit on ignition quality.

Experimental hardware - A single-cylinder version of a Caterpillar 3176/C-10 diesel engine has been modified at Sandia to allow extensive optical access into the combustion chamber. The typical application of the production engine is in Class 7-8 heavy-duty trucks. A cross-sectional view of the optical engine is shown in Fig. 5. The combustion chamber is symmetrical about the axis of the centrally-located, vertical injector. One unique feature of the Sandia/Caterpillar optical engine is that the cylinder head was modified to use a GP to shorten the ignition delay of low-cetane-number alternative fuels to within limits suitable for application in this diesel engine.

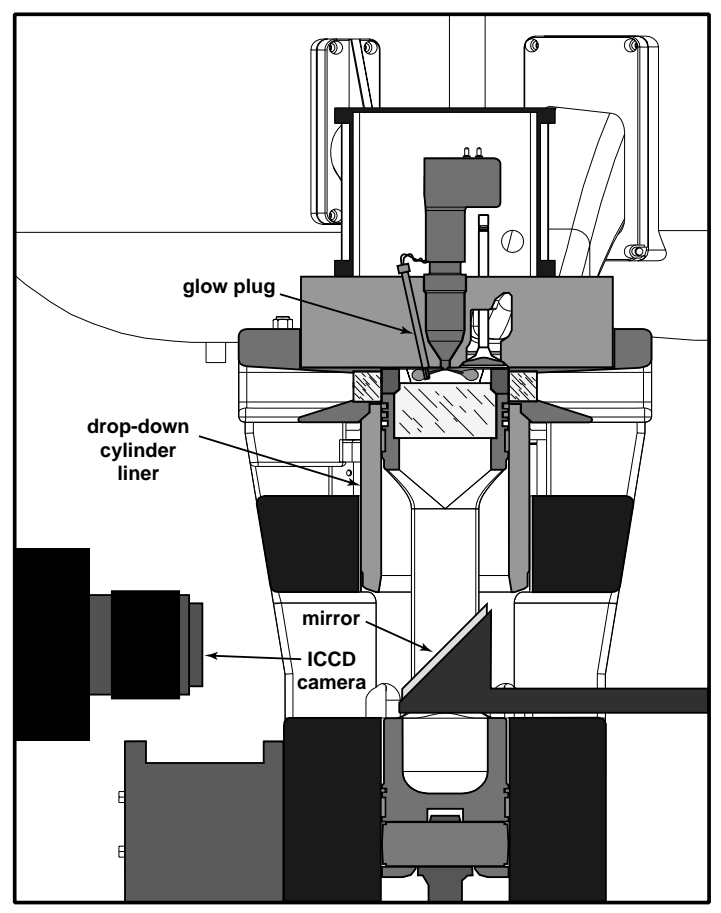

Figure 5. Cutaway schematic of Sandia/ Caterpillar single-cylinder engine.

Recent results - GP-assisted ignition and combustion of neat methanol (M100) was studied at a 1200-rpm, moderate-load operating condition. M100 results were compared to results obtained at the same operating condition but using a 45-cetane blend of diesel primary reference fuels (CN45). Sequences of images of direct luminosity (DL) were coupled with thermodynamic analyses of measured cylinder pressure data to gain insight into in-cylinder processes that are vastly different between the low-cetane M100 fuel and the CN45 reference fuel. The following conclusions are drawn:

1. Both proper GP temperature and proximity to a fuel jet are critically important for smooth engine operation when the low-cetane M100 fuel is used. Once an acceptable temperature and orientation of 
the GP is established, very stable engine output power can be achieved at TDC charge temperatures typical of current heavy-duty diesel engines.

2. M100 ignition is observed to occur at the GP, as expected. Combustion first spreads to the two jets straddling the GP, then jumps to adjacent pairs of jets as it makes its way to the side of the combustion chamber opposite the GP. Each pair-wise jet ignition event observed in the M100 DL image sequence correlates with a spike in the AHRR profile, as shown in Fig. 6.

3. Analysis of spatially-integrated DL data for the two fuels suggests that in-cylinder soot levels during M100 combustion are reduced by at least 2 orders of magnitude relative to $\mathrm{CN} 45$.

4. Cyclic variability in the start of combustion and the peak cylinder pressure was an order of magnitude larger for M100 operation than for CN45 operation, but cyclic variability in engine output power for both M100 and CN45 remained below 1\%.

5. Comparison of measurements of the engine work output and of the quantity of fuel injected for M100 and CN45 showed that the combustion efficiency of M100 is approximately equal to unity at this operating condition.

6. Engine operation was noticeably quieter for $\mathrm{M} 100$ than for CN45. This was explained by observing that peak AHRR values during M100 combustion were half those attained during CN45 combustion. GP

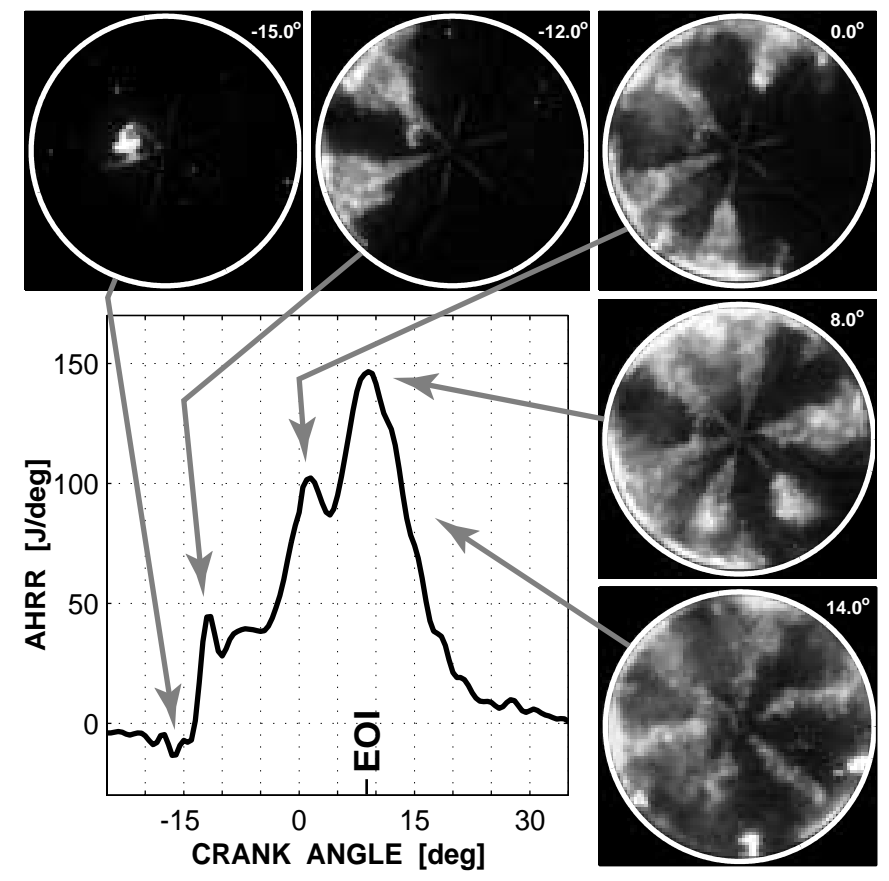

Figure 6. Pair-wise jet ignition events observed in DL images of M100 combustion correspond to peaks in apparent heat release rate (AHRR). Number in upper-right corner of each image is crank angle at image acquisition $\left(0^{\circ}\right.$ is top dead center). White circle indicates location of piston bowl wall. Fuel jets emanating from injector are visible in first four images due to elastic scattering of $D L$ from liquid fuel droplets. ignition-assist enables a low-cetane fuel to produce significantly less combustion noise than a typicalcetane fuel.

$\mathrm{HCCl}$ ENGINE- A new project is underway to investigate homogeneous-charge, compression-ignition ( $\mathrm{HCCl})$ engine combustion. $\mathrm{HCCl}$ offers the potential for verylow emissions and diesel-like efficiencies. It is not a new idea but one that is being considered more seriously because of the very stringent Tier II light-vehicle and 2007-2010 highway-truck emission standards. The concept involves premixing the fuel and air, and then compressing the mixture until combustion occurs throughout the volume. This volumetric compressioninduced combustion can occur under very lean conditions, at which combustion cannot be achieved with traditional diesel or spark-ignition engines. Under these conditions, combustion temperatures are low, and very little $\mathrm{NO}_{\mathrm{x}}$ is produced. Particulate emissions are also low because the charge is lean and well-mixed. Efficiencies can be as high or higher than those of a diesel engine for three reasons: 1 ) the compression/expansion ratio can be high, comparable to that of a diesel engine, 2) there are no throttling losses, and 3) the heat release is closer to constant volume than that of either a diesel or sparkignition engine.

However, there are several challenges to building a practical $\mathrm{HCCl}$ engine. Five of the most significant include: 1) maintaining proper ignition timing as the engine load and speed are varied; 2) controlling the combustion rate to allow operation at higher loads; 3 ) minimizing engine-out emissions of hydrocarbons $(\mathrm{HC})$ and carbon monoxide (CO), particularly at light load; 4) developing techniques for reliable cold start; and 5) developing control systems to allow smooth operation through rapid transients.

The objective of our program is to provide the fundamental understanding of $\mathrm{HCCl}$ engine combustion (i.e., the science base) required by industry to overcome these challenges. The project has both an experimental and a modeling component.

Experimental hardware - An $\mathrm{HCCl}$ engine laboratory is being established that will be equipped with two engines of the same basic design. One, an all-metal engine, will be used to establish operating points, develop combustion-control strategies, and investigate emissions. The other, an optically accessible engine, will be used to apply advanced laser-based and other optical diagnostics to investigations of in-cylinder processes.

Since no $\mathrm{HCCl}$ production engines exist today, two Cummins B-series diesel engines are being converted into the $\mathrm{HCCl}$ research engines. This sport utility vehicle-sized engine (0.98 liters/cylinder) was selected as being capable of providing an operating range relevant to both automotive and heavy-duty manufacturers. It can operate at speeds up to $3600 \mathrm{rpm}$ and is capable of operation at the high compression ratios necessary to achieve diesel-like efficiency. The 
six-cylinder production engines are mounted on either end of a double-ended dynamometer and are being converted for balanced, single-cylinder $\mathrm{HCCl}$, operation.

The engines and support facility are designed to provide the flexibility needed to investigate a wide variety of HCCl-like operating modes across a wide load/speed range. This capability is necessary in order to understand the controlling physics of $\mathrm{HCCl}$ combustion and to investigate the potential of various methods for controlling $\mathrm{HCCl}$ engines. The main features of the laboratory include:

1. Compression ratio easily adjustable from $13: 1$ to 21:1.

2. Multiple fueling systems (fully premixed, port injection, and direct injection).

3. Capability of using various fuel types

4. Intake charge tailoring (temperature, pressure, and intake-gas composition).

5. EGR/residual-gas mixing

6. Variable-swirl capability by customized intake-valve porting.

7. Optically accessibly engine

8. Variable valve timing (VVT)

Construction of the $\mathrm{HCCl}$ laboratory is well underway. The all-metal engine is expected become operational by mid 2001, with the optical engine coming on-line in 2002. the three fuel systems, and the design of the optically accessible engine are almost finished.

Modeling results - This project also involves a computational modeling effort using the Senkin software package [12]. For this work, the code has been modified to allow time-varying compression, which gives a good representation of the bulk-gas behavior in an $\mathrm{HCCl}$ engine. The detailed chemical reaction mechanisms for $\mathrm{n}$-heptane and iso-octane are used to investigate the effects of fuels with different ignition qualities (e.g., gasoline and diesel fuel). Using this code, numerous investigations have be conducted of how operating conditions and fuel types affect ignition timing, combustion, and emissions formation ( $\mathrm{HC}$ and $\mathrm{CO}$ ). These computations provide insight into the controlling parameters and operating sensitivity of $\mathrm{HCCl}$, which guide the engine design and experimental plans.

Initial CHEMKIN modeling results [13] showed that the ignition qualities of gasoline-like fuels have significant advantages for $\mathrm{HCCl}$. Specifically, gasoline-like fuels allow the use of the high diesel-like compression ratios that are needed for high efficiencies, and with these fuels, the ignition timing is relatively insensitive to changes in fuel loading, simplifying engine control. In addition, gasoline-like fuels are easily vaporized,

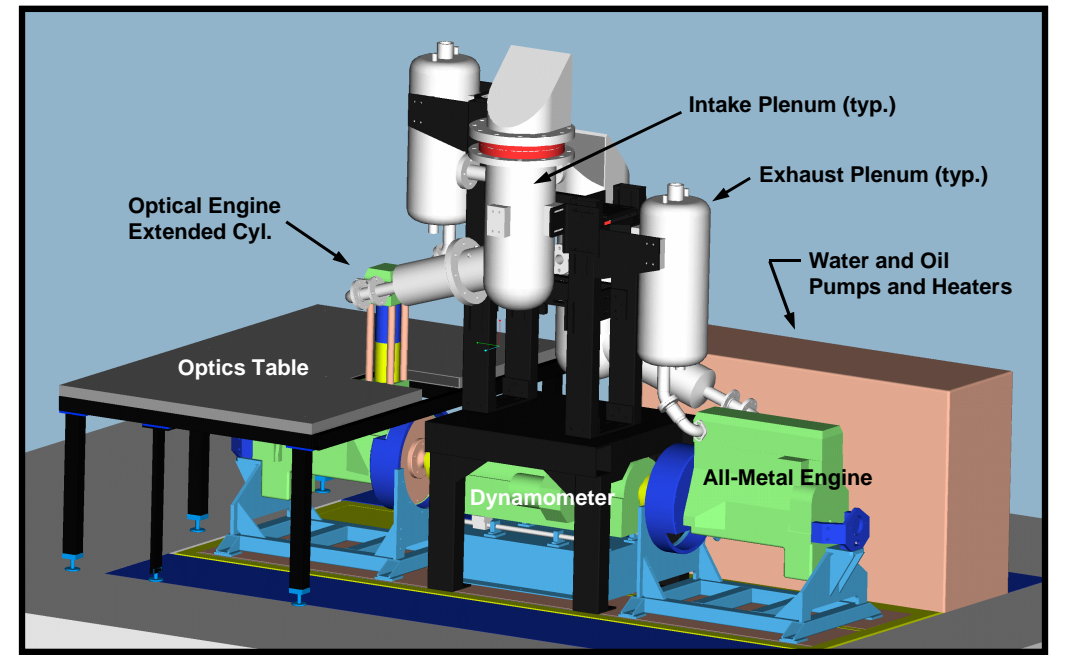

Figure 7. A schematic of the $\mathrm{HCCl}$ laboratory showing both the all-metal and optical engines installed.

A VVT system for the all-metal engine also planned for 2002. Figure 7 shows a schematic of the laboratory as it will look after both engines are completed. With the exception on the extended cylinder of the optically accessible engine, assembly of the laboratory as per the schematic is essentially complete. In addition, the intake-charge mixing, metering, and conditioning system, simplifying mixture preparation.

More recent computational investigations have focused on understanding the kinetic limits of low-load operation, using iso-octane as a surrogate fuel for gasoline. Figure 8 shows that the heat release rate of fully homogenous $\mathrm{HCCl}$ combustion slows as fuel loading (equivalence ratio) is reduced. This results in a significant reduction in 


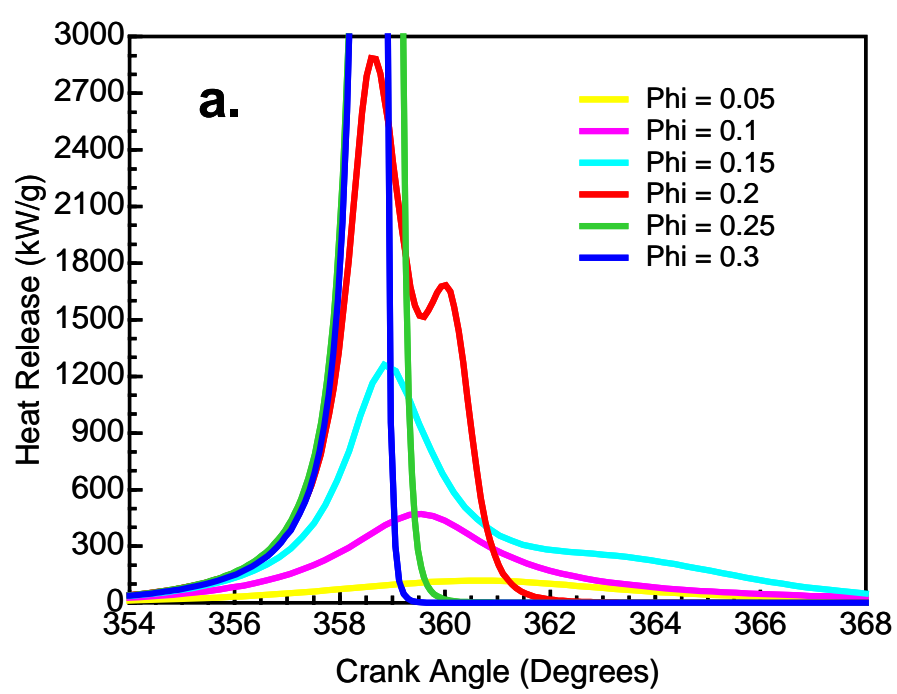

Figure 8. The effect of equivalence ratio $(\phi) \mathrm{HCCl}$ combustion heat release rate.

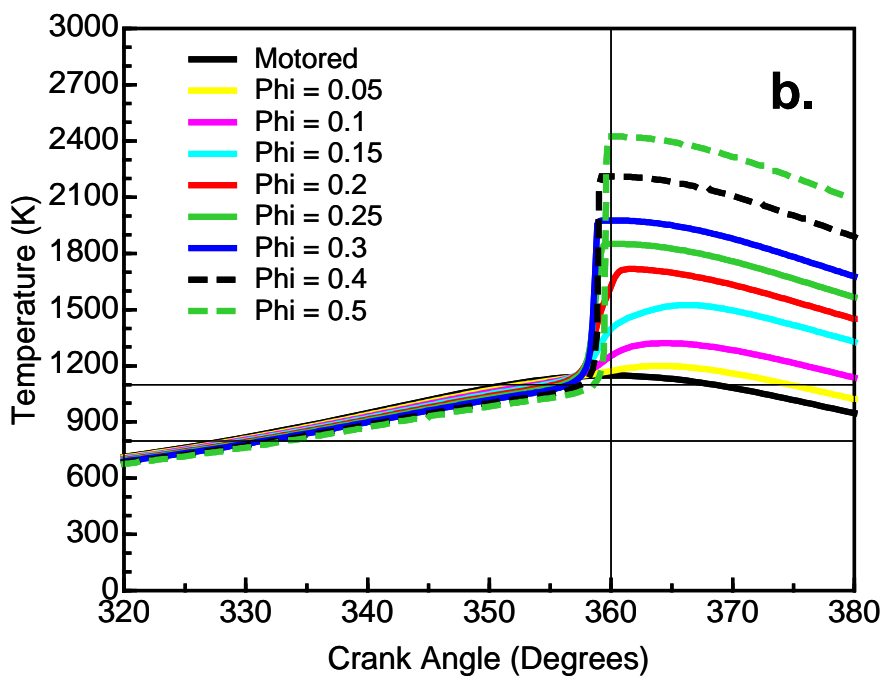

Figure 9. The effect of equivalence ratio $(\phi)$ on the temperature rise due to $\mathrm{HCCl}$ combustion

the rate of temperature and pressure rise for equivalence ratios 0.2 and lower as shown in Fig. 9. This slower combustion chemistry is advantageous in that it helps the engine operate smoothly with low noise.

However, further investigation showed that as the combustion chemistry slows, a point is eventually reached where the combustion reactions do not go to completion. This effect is first noticed at an equivalence ratio of about 0.15 , and becomes progressively worse as the fuel loading is reduced toward idle (equivalence ratios of 0.05 to 0.1 ). It should be noted that these results are for the bulk-gas behavior and that, in a real engine, wall heat transfer will cool the gases near the wall increasing the magnitude of these effects, shifting their onset to higher equivalence ratios.
The results of these kinetic computations provide an explanation for the high levels of $\mathrm{HC}$ and $\mathrm{CO}$ emission typically observed from $\mathrm{HCCl}$ engines operating at low loads, and have implications for the design of low-load $\mathrm{HCCl}$ combustion strategies.

\section{ACKNOWLEDGMENTS}

This work was performed at the Combustion Research Facility, Sandia National Laboratories, Livermore, CA. Funding support was provided by the U.S. Department of Energy, Office of Heavy Vehicle Technologies. The authors would also like to express their appreciation to the principal investigators of the projects described above: Mark Musculus (Sandia/Cummins engine), Dennis Siebers (diesel combustion simulation vessel), Chuck Mueller (Sandia/Caterpillar engine), and John Dec (Sandia/Cummins and $\mathrm{HCCl}$ engines).

\section{REFERENCES}

1. Dec, J. E. and Kelly-Zion, P., "The Effects of Injection Timing and Diluent Addition on LateCombustion Soot Burnout in a DI Diesel Engine Based on Simultaneous 2-D Imaging of $\mathrm{OH}$ and Soot, SAE paper no. 2000-01-0238, 2000.

2. Dec, J. E. and Tree, D. R., "Diffusion-Flame/Wall Interactions in a Heavy-Duty DI Diesel Engine," SAE paper no. 2001-01-1295, 2001.

3. Tree, D. R. and Dec. J. E., "Extinction Measurements of In-Cylinder Soot Deposition in a Heavy-Duty DI Diesel Engine," SAE paper no. 200101-1296, 2001.

4. Naber, J.D. and Siebers, D.L., "Effects of Gas Density and Vaporization on Penetration and Dispersion of Diesel Sprays," Transactions of the SAE, Vol. 105, Sec. 3, pp. 82-111, (SAE paper no 960034) 1996.

5. Siebers, D.L. and Higgins, B.S., "Flame Lift-Off on Direct-Injection Diesel Sprays Under Quiescent Conditions," SAE2001-01-0530, 2001.

6. Higgins, B.S. and Siebers D.L., "Measurement of the Flame Lift-off Location on DI Diesel Sprays Using OH Chemiluminescence," SAE2001-01-0918, 2001

7. Siebers, D.L. and Higgins, B.S., "Effects of Injector Conditions on the Flame Lift-Off Length of DI Diesel Sprays," Conference on Thermal Fluid Dynamic Processes in Diesel Engines, Sept. 14-15, 2000.

8. Siebers, D.L., "Liquid-Phase Fuel Penetration in Diesel Sprays," Transactions of the SAE, Vol. 107, Sec. 3, pp. 1205-1227, (SAE paper 980809) 1998.

9. Siebers, D.L., "Scaling Liquid-Phase Fuel Penetration in Diesel Sprays Based on MixingLimited Vaporization," SAE1999-01-0528, (SAE paper 1999-01-0528) 1999.

10. Kalghatgi, G.T., "Lift-off Heights and Visible Flame Lengths of Vertical Turbulent Jet Diffusion Flames in 
Still Air," Combustion Science and Technology, Vol. 41, pp. 17-19, 1984.

11. Mueller, C.J. and Musculus, M.P., "Glow Plug Assisted Ignition and Combustion of Methanol in an Optical DI Diesel Engine," SAE Paper 2001-01-2004, 2001.

12. The CHEMKIN program and subroutine library are part of the Chemkin Collection. R. J. Kee, F. M. Rupley, J. A. Miller, M. E. Coltrin, J. F. Grcar, E. Meeks, H. K. Moffat, A. E. Lutz, G. Dixon-Lewis, M. D. Smooke, J. Warnatz, G. H. Evans, R. S. Larson, R. E. Mitchell, L. R. Petzold, W. C. Reynolds, M. Caracotsios, W. E. Stewart, and P. Glarborg, Chemkin Collection, Release 3.6, Reaction Design, Inc., San Diego, CA (1999).

13. Kelly-Zion, P. L. and Dec, J. E., "A Computational study of the Effects of Fuel-Type on Ignition Time in $\mathrm{HCCl}$ Engines," $28^{\text {th }}$ International Symposium on Combustion, The Combustion Institute, 2000. 